\title{
ENTENDENDO O TOQUE TERAPÊUTICO
}

\author{
Maria Julia Paes da Silva* \\ Arlete Silva * \\ Carmen Aparecida da Silva Cruz **. \\ Joana Darc Lucena de Almeida ***
}

\begin{abstract}
RESUMO - O presente artigo tem por objetivo fornecer uma visão do que é o toque terapêutico proposto por Dolores Krieger. Para isto, discorre-se sobre conceitos do toque e do toque terapêutico (TT), tendo como referencial teórico a concepção energética da natureza. Cita as bases conceituais para entender o processo de cura através do toque terapêutico, atributos importantes que devem ser observados pela pessoa que o utilizará como intervenção e sua técnica com as 5 fases. Exemplifica, mostrando resultados conseguidos após sua aplicação, em experimentos americanos.
\end{abstract}

\begin{abstract}
The present article aspects of the therapeutic touch described and proposed to nurses by Dolores Krieger. She makes an explanation of the concepts of touch, energy and therapeutic touch (TT). The conceptual bases are pointed out to understand the cure process of the T.T. and the technics in five stages. She gives exemples which are results of TT application.
\end{abstract}

\section{INTRODUÇĀO}

\section{Conceitos gerais de toque}

A pele é o mais sensível e antigo de nossos órgãos, o primeiro meio de comunicação com o mundo. É através dela que o organismo aprende o seu ambiente, que o mundo externo é percebido; é a proteção para os tecidos do interior do corpo, conforme relata MONTAGU ${ }^{16}$.

A pele é a base dos receptores sensoriais, onde está localizado o mais delicado de todos os sentidos, o tato, o primeiro a surgir e a desenvolver-se no embrião humano, diz o autor.

Muitas expressōes usadas no nosso dia-adia, referem-se às funções da pele, como por exemplo: "dar um toque" (telefonar) para alguém; "toque pessoal" referindo-se a algo mais que o ato mecânico; pessoa cheia de "não-metoques" para pessoa hipersensível; pessoas que "têm tato" ou "não têm tato" no tratamento com outras, e assim por diante, segundo MONTAGU $^{16}$.

$\mathrm{O}$ toque tem sido relacionado a uma das formas mais importantes da comunicação nãoverbal e pode enviar mensagens positivas e negativas para as pessoas, afirmam BLONDIS, JACKSON', LE MAY ${ }^{13}$.

$\mathrm{O}$ toque pode transmitir sentimentos de simpatia, interesse, preocupação, aceitação, segurança, por contribuir na redução da ansiedade e proporcionar bem-estar físico e psicológico; pode tamberm transmitir sentimentos de hostilidade, raiva, medo e, como as outras formas de comunicação não verbal, precisa ser validado e interpretado no conteẋto em que ele ocor$\mathrm{re}^{1},{ }^{7},{ }^{17},{ }^{19}$.

LE MAY ${ }^{13}$, citando Watson, define o toque como um contato físico intencional entre duas ou mais pessoas e classifica-o em instrumental e expressivo.

Toque instrumental é o contato físico deliberado, necessário para o desempenho de uma específica tarefa; toque expressivo é um contato relativamente espontâneo e afetivo, não necessariamente relacionado a uma tarefa física ${ }^{13}$.

Durante a rotina diária, as enfermeiras tocam com freqüência no paciente, mas raramente usam toque expressivo.

LE MAY ${ }^{13}$ e DAVIS ${ }^{5}$ adyertem que o toque deve ser usado de forma cuidadosa, considerando-se a privacidade e espaço pessoal do paciente, suas diferenças individuais, culturais e o seu consentimento.

\section{Concepçāo energética da natureza}

Desde o Século XVII que a física tem sido o exemplo de uma ciência exata e servido como modelo para todas as outras ciências. Durante

\footnotetext{
* Enfermeira, Assistente do Departamento de Enfermagem Médico-Cirúrgica - EEUSP.

** Biologista, Laboratório do Centro Cirúrgico do HCFMUSP.

*** Enfermeira, Prof. Adjunto. Depto de Enf. Univer. Federal de Mato Grosso
} 
aproximadamente 2 séculos e meio, os físicos se utilizaram de uma visão mecanicista do mundo para desenvolver a estrutura conceitual do que $\varepsilon$ conhecido como física clássica, baseando suas idéias na teoria matemática de Isaac Newton, na filosofia de René Descartes e na metodologia cientffica defendida por Francis Bacon ${ }^{3},{ }^{18}$.

Nessa estrutura conceitual, que ainda hoje é a base à compreensão do homem e do mundo para a maioria das pessoas, a matéria é a base de toda a existência, o mundo é uma gigantesca máquina composta de peças elementares e os fenômenos podem ser compreendidos desde que reduzidos a seus componentes básicos.

No Século XX, a física passou por revoluções conceituais que mostram as limitações dessa visão mecanicista e levam a uma visão orgânica, ecológica, também semelhante a visão dos místicos de todas as épocas ${ }^{18}$.

$\mathrm{Na}$ concepção dessa "nova" física, chamada física quântica (quantum = quantidade específica de algo), o universo deixa de ser visto como uma máquina, composta por um infinito de objetos, para ser descrito como um todo dinâmico, indivisivel, cujas partes estão essencialmente interrelacionadas e só podem ser entendidas como modelos de um processo cósmi$\mathrm{CO}^{3},{ }^{4}$.

Nas experiências realizadas pelos físicos, observou-se que os átomos "não são partículas duras, sólidas, mas vastas regiões de espaço onde partículas extremamente pequenas - os elétrons - se movimentam ao redor do núcleo. Essas partículas subatômicas - os èlétrons, prótons e neutrons no núcleo - são entidades muito abstratas e têm um aspecto dual: dependendo do modo como as observamos, apresentam-se ora como partículas, ora como ondas" 3 .

A fŕsica clássica descreve coisas, objetos individuais no espaço e suas mudanças no tempo, prediz acontecimentos, admite uma realidade objetiva "fora daqui" e aceita que, possamos observar algo sem modificá-lo; enquanto que a fŕsica quântica descreve condutas estatísticas de sistemas, prediz probabilidades, não aceita uma realidade objetiva separada de nossa experiência e que podemos observar algo sem modificá-lo.

É bom lembrar, que a física quântica não substitui a física newtoniana. Porém, ela continua válida dentro de seus limites. $O$ que os físicos neste século XX descobriram, é que a forma como se vinha observando a natureza não é suficientemente compreensível para explicar tudo quanto podemos observar.

A mais importante conseqüência dessa nova estrutura conceitual, $e$ a compreensão de que $a$ massa nada mais é senão uma forma de energia ${ }^{3},{ }^{i \dot{s}}$. Nos processos de colisão de alta energia, em física, as partículas materiais serão criadas e destruídas, sendo suas massas transformadas em energia de movimento e vice-versa"'s.

A ciência moderna tomou consciência de que todas as teorias científicas são aproximações da verdadeira natureza da realidade, e também entendeu que cada teoria é válida para uma certa gama de fenômenos.

CAPRA $^{3}$ refere que a pesquisa biomédica terá que ser integrada num sistema mais amplo de assistência à saúde, em que as manifestações das enfermidades sejam vistas como resultantes da interação corpo, mente e meio ambiente.

Os conceitos de saúde e doença precisam ser repensados nesse novo paradigma, onde o organismo humano é visto como um microcosmo do universo, e as flutuações entre equilibrio e desequilíbrio são vistas como um processo natural que ocorre ao longo de todo o ciclo vital.

É dentro dessa estrutura conceitual que o toque terapêutico deve ser estudado e compreendido.

\section{Conceitos gerais do toque terapêutico}

O toque terapêutico, termo que vem sendo usado mais recentemente para a imposição de mãos, é uma técnica terapêutica que tem sido aplicada há muito tempo.

As bases conceituais para entender o processo de cura do toque terapêutico são apresentados por BUGUSLAWSKI ${ }^{2}$.

- o homem é um campo de energia;

- o homem e o ambiente estão contínuamente, simultâneamente e mútuamente trocando energia um com o outro, entendendo-se por ambiente todo o exterior do homem, inclusive outra pessoa;

- a ordem universal é uma força inata a todo campo de energia.

Este campo energético, ou força vital, é uma forma de energia eletromagnética; é a corrente animadora da vida ${ }^{8}$.

É empregando as correntes de força vital, que fluem naturalmente das mãos de todas as pessoas, que se pode aliviar a dor, ansiedade e equilibrar a energia de outra pessoa.

A força vital tem sido chamada por diferentes nomes, através dos tempos. Assim, Cristo o chamou "luz"; os russos de "energia bioplasmática"; Wiehelm Reich de "energia orgone"; os yogues da India Oriental de "pran" ou "prana"; Paracelso chamou-a "munia"; os chineses de "chi" ou "ki"; Hipócrates de "força vital da natureza"; Bruner de energia "biocósmica". É chamada também de bioenergia, energia cósmica, éter do espaço, etc ${ }^{8}$.

Segundo GORDON", "a energia vital flui através do corpo como se estivesse seguindo um sistema circulatório invisível, carregando toda célula no seu caminho. Esta corrente de energia pode tomar-se enfraquecida e parcialmente bloqueada devido ao cansaço". 
As técnicas do toque físico e não físico realizadas para repadronizar a energia através de todo o organismo, abrindo os pontos bloqueados e restabelecendo, assim, o fluir natural e o alinhamento da força vital através do corpo.

BOGUSLAWSKI $^{2}$ propõe alguns atributos e conceitos importantes que devem ser observados pela pessoa que utilizará o toque terapêutico como intervenção:

- primeiro, é ter a intenção de ajudar o outro, querer que aquela pessoa sinta-se bem;

- segundo, é ter habilidade de concentração; o toque terapêutico é um processo consciente, que não pode ser desenvolvido de maneira descuidada, com o pensamento em outro lugar;

- terceiro, é ter habilidade para centralizar-se;

- quarto, é importante que o terapeuta não se sinta cansado, sinta-se bem, pois se ele não for capaz de centralizar-se, em vez da fonte universal de energia, é a sua energia pessoal que será usada;

- quinto, o terapeuta está transmitindo a energia universal, ordenada, que existe dentro de todos nós e no ambiente, e não sua energia pessoal;

- sexto, outro conceito importante e difícil para os iniciantes internalizarem, é o "esforço sem esforço"; se o terapeuta centraliza e tem a intenção de ajudar o cliente, a unicidade do terapeuta com o ambiente e o desejo do cliente em estar bem, fará com que naturalmente a energia necessária se ja captada pelo cliente;

- sétimo, é importante que o terapeuta sugira ao cliente exercícios de visualização, que envolvem a criação de uma figura mental que possa auxiliar o cliente na repadronização da energia.

\section{TÉCNICA DO TOQUE TERAPÊUTICO (T.T.) - DOLORES KRIEGER}

Toque terapêutico refere-se, no presente trabalho, à técnica descrita pela enfermeira Dolores Krieger ${ }^{1}$. Esta autora desenvolveu a técnica após estudar a medicina oriental, a ioga e uma investigação sobre imposição de mãos conduzida por Dora Kunz, observadora da cura paranormal.

Através de uma sistemática pesquisa das práticas terapêuticas de todo o mundo, reconheceu um universo de expressões, indicando o sentido subjetivo e intuitivo das práticas entre os terapeutas das diferentes culturas.

No livro "Toque Terapêutico", KRIEGER' nos descreve de maneira acessível, a metodologia empregada. A idéia de "milagre" é descartada e aflora a valorização do poder natural de cura do próprio homem. Esta autora descreve o terapêutico como um ato de cura, que tem sido praticado por séculos na India, onde yogues escreveram sobre a energia curativa, que é chamado por eles de prana.

A terapia do toque $\epsilon$, em primeiro lugar, um ato consciente de intervenção terapêutica ${ }^{11} \mathrm{e}$, principalmente, um ato de direcionar e manter durante todo processo, um estudo de tensão livre e de intenção de cura. $O$ toque terapêutico emprega um esforço meditativo para ajudar o paciente a repadronizar a sua energia; tem a função de acelerar o processo de cura, pois como enfatiza KRIEGER ${ }^{1}$, só o paciente pode curar totalmente a si mesmo.

O processo de terapia do toque pode ser descrito em cinco fases ${ }^{1}$ :

1. Centralização do Terapeuta ciente

2. Avaliação do Campo Energético do Pa-

3. Dinamização do Campo

4. Direção e Modulação da Energia

5. Reavaliação do Campo

Inicialmente, a concentração do terapeuta tem por finalidade sua centralização, com $o$ intuito de desenvolver um estado de equilibrio interno, obtido através de exercícios próprios e simples, como por exemplo, sentar-se relaxadamente e alinhadamente, ,. passando a executar movimentos de tronco lateral e ritmicamente, tentando localizar as áreas de tensão e desfazêlas, até que sobrevenha uma sensação de bem estar.

MACRAE ${ }^{14}$ cita a importância da centralização, que consiste no ato de se recolocar conscientemente em um estado de calma, de alerta, de interação de si mesmo com o aqui e agora.

Em seguida, vem o que se pode chamar pelo terapeuta de Avaliação, 'onde ele sente, com a imposição das mãos a uma distância de 3 a 5 $\mathrm{cm}$ da pele do paciente, o campo energético do mesmo. Nesta etapa, deve ser considerada a motivação do terapeuta para a cura. $O$ terapeuta percebe diferenças no campo energético do paciente, detectando locais com diferentes temperaturas, formigamento, diferença de pressão, etc.

Uma vez detectado o campo energético, inicia-se o processo de descongestionamento do fluxo energético, ou seja, a Dinamização desse campo. Observa-se então, a transferência da energia pelo deslocamento desta, através do terapeuta para o paciente, ou de um lugar para outro, no próprio campo do paciente. Nesta fase, há uma simultaneidade de açōes: a Direção e a Modulação de energia para a cura, além de uma troca energética que ocorre no momento em que o terapeuta pensa em iniciar o processo, estabelecendo assim uma relação harmoniosa.

Após essa fase de Direção e Modulação, vem em seguida a Reavaliação do campo energético para a verificação da harmonia do mesmo. As fases mencionadas anteriormente, 
podem se sobrepor à medida em que o terapeuta vai se desenvolvimento e treinamento esta técnica. Portanto, a duração do toque varia segundo a capacidade do terapeuta em se centralizar, reconhecer o campo energético do paciente e redirecioná-lo.

Comumente, nos relatos de KRIEGER ${ }^{10},{ }^{11}$, ${ }^{12}$, existe uma grande motivação para o desenvolvimento do auto-conhecimento do terapeuta e, através da consciência aberta, este estará apto ao envolvimento terapeuta-paciente.

Reforçamos que a energia envolvida no processo será transferida ao paciente, através do terapeuta, sem esforço e de um modo natural, ou deslocada de um local para outro no paciente, conforme a necessidade. É de grande valia que se entenda que o terapeuta é um canal ou condutor de energia, e nunca um gerador desta.

À medida em que o terapeuta desenvolve esta prática, passa a apresentar mudanças na sua capacidade de sentir o outro, desenvolvendo faculdades naturais de comunicação e tendo maior facilidade de explorar sua propria mente inconsciente. É relevante lembrar que independente do toque terapêutico resultar em cura, ele sempre proporciona ao paciente um estado de relaxamento, bem estar, paz, harmonia e diminuição da ansiedade.

\section{Experimentos com o Toque Terapêutico (T.T.)}

Várias pesquisas experimentais foram desenvolvidas para tentar compreender o processo do T.T., justificá-lo científicamente e demonstrar sua eficácia; entre elas, podem ser citadas:

1 - Para tentar medir o T.T. através de procedimentos padronizados, o bioquímico Bernard Grad usou sementes de cevada, divididas igualmente em três grupos: grupo experimental A e grupos controles B e C. As sementes A, irrigadas com água energizada pelo terapeuta Estebany, brotaram mais rapidamente, os brotos cresceram mais alto e as plantas tinham mais clorofila. Os grupos controles, irrigados com outro tipo de água, não apresentaram tais características ${ }^{10},{ }^{12},{ }^{15}$.

2 - Em um outro experimento com 300 camundongos, foram feitas lesoẽs semelhantes de pele, nas costas de todos eles. Foram divididos em três grupos iguais. O grupo experimental I, energizado pelas mãos do terapeuta Estebany, mostrou taxas de cura fortemente significativas. $\mathrm{O}$ mesmo não aconteceu com o grupo controle II, tratado de maneira diferente, e também com o grupo controle III, energizado por não terapeụtas, de modo idêntico ao grupo $\mathrm{I}^{12},{ }^{15}$.

3 - KRIEGER ${ }^{12}$ realizou vários experimentos em grupos de pessoas, para verificar se os valores de hoglobina aumentariam depois do Г.T. À medıda que as pesquisas foram sendo desenvolvidas, a autora conseguiu controlar possíveis variáveis interferentes, como idade, sexo, medicação, dieta, fumo, recentes traumas, etc., e, em um dos estudos realizados em 1972, as hipóteses foram novamente confirmadas e os valores de hemoglobina mostraram-se significativamente aumentados, ${ }^{10},{ }^{12},{ }^{15}$.

4 - MACRAE ${ }^{14}$ nos relata um experimento que mostrou a importância em se perceber o campo de energia, quando ao impostar as mãos sobre um garoto de 10 anos com leucemia, ele referiu que a dor sentida no seu abdômem foi para suas pernas, e depois saiu pelos seus pés, à medida que movimentava as mãos pelo seu cor$\mathrm{po}^{14}$.

5 - Para ajudar na compreensão do processo do T.T., temos a fotografia Kirlian, que gera controvérsia quanto à sua validade, mas mostra um aumento do campo de energia nos seres humanos após a aplicação da técnica ${ }^{10},{ }^{12},{ }^{15}$.

6 - HEIDT ${ }^{9}$ relata uma pesquisa dos efeitos do T.T. no nível de ansiedade em pacientes hospitalizados. Ela trabalhou com 90 pacientes hospitalizados, divididos em 3 grupos, em uma unidade cardiovascular de um hospital geral de Nova York, com idade variando de 21 a 65 anos. O 10 grupo recebeu o T.T., o $2^{\circ}$ grupo recebeu o toque casual e o $3^{\circ}$ grupo não foi tocado. Os resultados mostraram que o grupo que recebeu o T.T. apresentou score significativamente menor de ansiedade, e os outros dois grupos não tiveram diferenças significativas entre si.

\section{CONSIDERAÇŌES FINAIS}

A evolução de uma tecnologia e o estilo de vida inerente a uma cultura própria, entre outros fatores, nos faz repensar nos ef eitos do progresso no indivíduo, sob o ponto de vista de saúde física e psíquica.

Verifica-se uma gama de opções a favor da saúde, que podem ser válidas se treinadas e estudadas cientificamente como complemento para o viver bem, incorrendo o menos possível nós efeitos colaterais de fárma os no organismo e no alto custo da terapia alopárma.

As causas da revalorização práticas alternativas são várias e elas podem ser consideradas, de uma maneira geral, menos invasivas, mais humanas, mais acessíveis à grande maioria da população, alem do que podem ser aliadas a outros tratamentos. Outra possível causa seria a ineficácia dos tratamentos alopáticos em determinadas circunstâncias.

A natureza é vasta e complexa. O conhecimento do homem acerca dos recursos naturais que poderiam ser utilizados para a profilaxia e cura dos seus males orgânicos e psíquicos, ainda é muito limitada, porque, preconceituosa- 
mente, o homem muitas vezes só acredita naquilo que vê e na pesquisa científica ortodoxa, que tem, por sua vez, muitas limitações.

O toque terapêutico é uma técnica baseada numa filosofia de vida e numa concepção energética da natureza, tendo por finalidade mobilizar no doente sua capacidade de autocura e tentando sanar aspectos físicos, espirituais e psicossomáticos da doença.

O toque terapêutico valoriza o homem e dá a oportunidade para entender a potencialidade do organismo humano como fonte de cura para si e para os outros.

Consideramos importante que mais pesquisas sejam desenvolvidas sobre o assunto, entre outros aspectos já citados, também porque o embasamento do toque terapêutico reconhece a pessoa enquanto ser energético, que está em equilíbrio quando numa relação harmoniosa consigo mesma, com os outros e com a própria natureza. E, sobretudo, porque os seus resultados são bastante positivos !

\section{REFERÊNCIAS BIBLIOGRÅFICAS}

1 BLONDIS, M.N., JACKSON, B.E. Nonverbal Communication With Patients: back to the human touch. 2.ed. New York: John Wiley, 1982, cap. 1. p. 2-29: What is nonverbal communication?

2 BOGUSLAWSKI, M. The use of therapeutic touch in nursing. J. Contin.Educ.Nurs., v. 10. n. 4. p. 9-15, 1979.

3 CAPRA, F. O ponto de Mutação. São Paulo: Cultrix, 1982. 4 .O Tao da Física. São Paulo: Cultrix, 1973.

5 DAVIS, A.J. Listening and Responding. Saint Louis: Mosby, 1984. cap. 6. p. 13'-61: Growing old.

6 DOHER TY, ${ }^{*} \in$., JACKSON, N. Therapeutic touch. AARN News Lett: v. 42, n. 6, p. 11-3, 1986.

7 DURR, C.A. Hands that help. .. but now ? Nurs. Forum, v. 10. n. 4, p. 392-400, 1971.

8 GORDON, R. A cura pelas mãos ou a prática da polaridade. São Paulo: Pensamento, 1978. Seção I, p. 20-31.

9 HEIDT, P. Effects of therapeutic touch on anxiety level of hospitalized patients. Nurs. Res., v. 30. n. 1. p. 32-7, 1981.

10 KRIEGER, D. Alternative medicine therapeutic touch. Nurs. Times, v. 72. n. 15. p. 572-4, 1976.
11 KRIEGER, D. The touch - how to use your hands to help or to heal. Englewood Cliffs: Prentice - Hall, 1979.

12 . Therapeutic touch: the imprimatur of nursing. Am.J.Nurs., v. 75. n. 5. p. 784-87, 1975.

13 LE MAY, A. Therapeutic touch: the human connection. Nurs. Times, v. 82. n. 47, p. 28-30, 1986.

14 MACRAE, J. Therapeutic touch in practice. Am. J.Nurs., New York, v. 79. n. 4. p. 664-5, April,1979.

15 MILLER, L.A. An explanation of therapeutic touch using the science of unitary man. Nurs.Forum, v.18. n.3. p. 278-87, 1979.

16 MON TAGU, A. Tocar: o significado humano da pele. São Paulo: Summus, 1988, cap. 1. p. 21-60: A mente da pele.

17 PARKINSON, M.H. Therapeutic interation: In: SORESEN, K.C.; LUCKMANN, J. Basic Nursing: a psychophysiòlogic approach. 2. ed. Philadelphia: Saunders, 1986. cap. 5. p. 71-102.

18 WADELL, E. Quality touching to comunicate caring. Nurs. Forum, v. 17. n. 3. p. 288-92, 1979.

19 ZUKA V, G. A dança dos Mestres Wu Li. São Paulo: Cultura Espiritual, 1989. 